\title{
Values and Diversity of Organisational Work Ethicality: Lessons Learnt from Sri Lankan Entrepreneurs
}

\author{
G. D. V. R.Senadheera ${ }^{a}$ \\ University of Sri Jayewardenepura, Sri Lanka \\ H.D. Karunaratne ${ }^{b}$ \\ University of Colombo, Sri Lanka
}

\begin{abstract}
The aim of this paper is to examine values as a component of organisational work ethicality, uncovering the contextual realities of values and explore the diversity of work ethicality in the entrepreneurial context in Sri Lanka. Organisational work ethicality is explained through egoistic work ethicality, utilitarian work ethicality and deontological work ethicality. With a view to get a deeper understanding of the diversity of organisational work ethicality, a qualitative approach is adopted. Twelve entrepreneurs were selected for in-depth interviews. A thematic analysis was carried out for field notes with the support of NVivo 6 version. Findings of this study reveal that the entrepreneurial thinking and their interpretations derived different social meanings of organisational work ethicality. The final outcome shows that rather than single dominant work ethicality, a combination of work ethicalities was preferred by most of the entrepreneurs. Within this mix of ethicalities, deontological ethicality and egoistic work ethicality seem to be equally practised by the entrepreneurs. The utilitarian ethicality seems to be practised at a minimum level. As a result, the implicational value of this study lies on at the organisational level and policy making level to rethink and reestablish a mechanism to improve ethical aspects of the businesses in order to maximise social well-being while doing the right things for the society and strengthening shareholders' protection.
\end{abstract}

a. Dr. G. D. V. R. Senadheera is a Senior Lecturer at the Department of Business Administration, University of Sri Jayewardenepura, Nugegoda, Sri Lanka. E-mail: rupikavs@sjp.ac.lk

b. Prof. H. D. Karunaratne is a Professor in Economics at the Department of Business Economics, University of Colombo, Sri Lanka. 


\section{Keywords}

Business Ethics, Business Practices, Deontological Work Ethicality, Egoistic Work Ethicality, Entrepreneur, Utilitarian Work Ethicality, Values

\section{Introduction}

Values are socio-psychological concepts that occupy a prominent place across all social science disciplines (Rokeach, 1973).Values can be viewed as an individual's internalised beliefs capable of being changed and relatively permanent under some conditions (Miling \& Ravlin, 1998). People act according to their values (Rokeach, 1973). Schwartz and Bilsky (1987) identify values as cognitive depiction of three universal requirements, namely biological need, interactional requirements for interpersonal coordination, and societal demand for group welfare and survival. Values are major components of organisational ethics at the level of an organisation (Meglino \& Ravlin, 1998). The value system of an entrepreneur is vital to establishing an ethical organisation (Kuratko et al., 2004). Furthermore, Rokeach and Ball (1989) have pointed out that values can be changed using interventions that produce self-dissatisfaction (cited in Koivula, 2012). Accordingly, Roe (1999) identified values as a source of motivation for individual actions. McDaniel (2001) has also stated that a company's ethical climate influences the performance of employees and managers and their core values guide their ethical judgments (cited in $\mathrm{Al}-$ Khatib et al. (2004). Hisrich (1998) states that personal values may influence how entrepreneurs respond to the ethical problems they encounter. $\mathrm{He}$ further pointed out that the ethical issues and perceptions of entrepreneurs and of managers are very much alike. Chowdhury and Fernando (2010) stated that, the characteristics of a person's quality belief systems and personality may have a great impact on ethical cognition as antecedent behaviour. Roccas et al. (2002) state that the positive relationship among values, traits and actions. It is clear that values are reflected through traits. Nevertheless, the literature reveals inconsistency in the application of values in research and also the diverse range of empirical findings is still unclear. 


\section{Literature Review}

Values and ethics are mutually inclusive. Ethics is an ongoing and never ending process. The challenges of business ethics play a significant role in explaining how organisations exhibit business behaviour and practices in the market. Trevino and Nelson (1999) define ethics as the principles, norms and standards governing an individual or a group. Conformity with business ethics leads organisations to be concerned with what is good or bad and what is right or wrong in business practices and operations. In other words, business ethics refers to the ability of firms to pay attention to moral judgments, practices and commitments in decision making process (Becker \& Fritzche, 1987).

In the present context, the values of entrepreneurs automatically become the most significant determinant of ethics although there are different points of view on the ethical dilemmas confronted by the entrepreneur. However, entrepreneurs are at the centre as movers and shakers of intellectual and material wealth and shaping their respective societies with the way they utilise intellectual and material wealth (Senadheera et al., 2014). Conversely, the present day business practices have given rise to socio-economic issues around the world including global financial crises and economic downturns have reflected financial dishonesty and malpractices. As a result, many allegations are directed towards the whole business community. Specially, the general public argued that entrepreneurs are not interested in social well-being (Mayer et al., 2010) and that they have created their own operating framework according to their own will and also they are not ashamed of such behaviour. The aforesaid facts explain that the ethical considerations have been diminished and as a result corruption has become common phenomenon. Thus, the attention of general public towards the ethical practices of organisations has increased.

As a developing country in the Asian region, Sri Lanka recognises that the development of entrepreneurial enterprises is vital for rapid socioeconomic growth. A new era of entrepreneurialism has dawned and especially 'social entrepreneurship' where values and ethics are highly considered. Therefore, the aim of this paper is to explore values as a component of work ethicality, uncovering the contextual realities of values and organisational work ethicality. Further, it explores why the 
entrepreneurs follow their own set of values and organisational work ethicality which differs from person to person in the entrepreneurial context in Sri Lanka.

\section{Overview of Socio-Cultural Values, Ethics and Entrepreneurship in Sri Lanka}

Sri Lankan rulers in the past wrote in rock inscriptions principles, values, and guidelines that citizens needed to practice and these inscriptions were extremely important to record significant moments of the history of the country. The Badulla pillar inscription is one such evidence to prove that values and ethics of business were prominent in Sri Lankan society during the history. The main objective of these inscriptions was to establish an ethical framework to control and avoid the rise of unethical business practices in society and it had been assured security and welfare to the entrepreneurs as well to consumers. The king managed the values of the society, but also gained the trust of his people. Accordingly, the terms, ethics, business ethics, values, entrepreneurship and entrepreneur, are not words unknown in Sri Lankan society and business (Chandraraya, 1958; Paranavithana, 1966; Dias, 1987; Jayewardena, 2000). The application of business ethics in Sri Lankan society dates back to the 2nd century AD.

A limited research available in Sri Lanka in the area of entrepreneurship and business ethics points out a relatively new research field in the Sri Lankan context. The facts revealed by the entrepreneurs in Sri Lanka (public speeches, paper articles, and interviews) seem to imply that most of the successful Sri Lankan entrepreneurs started their entrepreneurial career without any business intention and they had left their homes in early youth and found small jobs in the cities with the help of their friends. Through these jobs they collected basic knowledge, experience and so improved their skills. They had no adequate exposure to formal education although they had attended school at some point in their lives; nevertheless, they were born with certain skills. Specially, their intuitive knowledge which enabled them to identify opportunities in the market and innovatively exploit those identified opportunities as a business organisation by taking risks. In indigenous management practices these entrepreneurs called as "Mudalali" (Trader). They had a clear vision and they worked with a vision. Consequently, blending with their vision with inborn characteristics and 
embedded values drove them to achieve success for themselves and their families. Research how found that entrepreneurs in the first generation possessed a high degree of social power. According to Perera and Buddhadasa (1992) the need for achievement as a means to gain social power is seen to be the prime motivator of the low country Sinhala entrepreneur and the successful entrepreneur is one who takes medium risks, is highly persevering, and is highly innovational (Perera \& Buddhadasa, 1992).

The quality and complexity of personal networks would be a key determinant of the entrepreneurial success (Perera, 1996; Premaratne, 2002).The traditional Sri Lankan entrepreneurs' behaviour and work style were characterised by a strong ethical work dedication to the task, long term business ambition, commitment to quality, and personal attention to the customer and also they adopted an authoritarian leadership style (Perera, 1996). The traditional culture in Sri Lanka has been diluted with the arrivals of colonisers. Western ideologies are embedded in the Sri Lankan culture. Many studies critically evaluate the application of western ideologies to analyze socio cultural issues of the context. The possibility of achieving industrial development through the application of western ideologies in developing countries has been challenged for many years (Nanayakkara, 1984). Once more Sri Lankan entrepreneurs' voyage has turned to other countries too (Karunarathna, 2009).

\section{Research Design}

Qualitative methods have generally been gaining acceptance in small business and entrepreneurship research (Perren \& Ram, 2004). Research in the qualitative paradigm is highly useful to analyze social phenomena. The researcher is a part of the research context and he/she would carefully analyze the particular findings of others and their transferability and the ability to be generalised on a more case-to-case basis. It would help to develop a generally agreed view under the multidimensional perspective of the construct "entrepreneur" (Patton, 2002).

In the Sri Lankan context people are highly culture bound (Nanayakkara, 1984). Therefore, the socio cultural impact over human behaviour within the Sri Lankan context cannot be avoided. As this study 
explores entrepreneurial values and ethics which a behavioural component of human beings a qualitative methodology is applied.

\section{Methodology}

Twelve cases (hereafter mentioned as, $\mathrm{C} 1$ to $\mathrm{C} 12$ ) were judgmentally selected, representing several industries including manufacturing and services in Sri Lanka. This study used in-depth- interviews and observations (Brett et al., 2002) as a method of collecting qualitative data for the study. In-depth interviews were carried out with entrepreneurs of selected case organisations in order to have an insight to values and ethics that are practised in such business contexts in Sri Lanka. Each interview lasted for one and half hours to two hours in average. Although the researcher requested the permission to tape record the interviews. All the selected entrepreneurs did not provide their consent for recording the interviews. Therefore, a written copy of the interviews was maintained. The names of the interviewees and the names of the organisations are not disclosed for confidentiality. Only proprietary entrepreneurs were selected for the interviews.

Thematic analysis (Stirling, 2001; Braun \& Clarke, 2006) and interpreting data analysis (Deem, 2002) are used to analyze the qualitative data of this study. The first step of thematic networks is that it systematises the extraction of basic themes and the second step is that the identified basic themes are grouped together to derive organising themes and integrated organising themes into global themes (Stirling, 2001). The thematic analysis is carried out using NVivo 6 with the assistance of the field notes.

\section{Data Analysis, Findings and Discussion Entrepreneurial Values}

Sri Lankan history proves that traditional entrepreneurial behaviour and work style are characterised by strong work ethics, dedication to the task, long term business ambition, and personal attention to customers was prominent. Further, the concepts of equity, justice, honesty, competence, creativity, caring, confidence, trust, courage, obedience, fairness, sharing were socially embedded and helped to maintain a united society. With the arrival of European many western value systems became part of the local value systems. 
The results of the interview data demonstrated that entrepreneurs are generally embedded with values, such as need for achievement (100 percent), innovation (100 percent), trust (50 percent), honesty (50 percent), care (42 percent), fairness (42 percent), self-confidence (100 percent), risk bearing (58 percent), power distance (100 percent), and social recognition (100 percent), long term versus short term (58 percent), uncertainty avoidance (33 percent) and self-confidence (100 percent) (Refer Figure 1). Though it is evident through the given percentages, the findings of this study reveal that the entrepreneurs possess different type of values in different degrees. The following extracts clearly depict that entrepreneurs possess a unique combination of values.

I'm a risk taker and not hesitant to take up challenges... (C4)

My mother taught us to speak the truth, not to tell lies and do our work on our own. My mother got me to learn things from the environment and showed us how to build relationships and trust among the others. (C 5)

You all know that I am the one who introduced this product to Sri Lanka for the first time when there were no local product as such and nobody even knew about such a product...I had to take up the challenge of introducing this alien product to the local community in order to create a new customer base... using my own strategies I have achieved that target successfully. (C2)

It is evident that a family is a culture-bound entity. A family's values are extended into all most all areas of life. In the entrepreneurial community family's values have become important. Entrepreneurs possess some values which they have derived from their family.

Further, the insights reflected that in entrepreneurial context in Sri Lanka, the most of case entrepreneurs do not reflect trust or honesty with their business practices (Refer Figure 1). It seems to be entrepreneurs who were reluctant to incorporate much of these values into their business. However, as persons they possess such values, but not as entrepreneurs. 
Existing scenarios and practices of the business context revealed by the entrepreneurs from case six and five are as follows:

To be honest, I show that I always trust my workers, but I trust only myself. I do not trust every worker and I am not too open with them about all the company details either. I do not believe that employees are fully faithful to the company. There should be a close supervision otherwise the resources might be misused. Therefore CCTV cameras, my computer and my mobile are focused on key areas of the business to govern my business carefully. (C 6)

People, even though they work hard, should be monitored. (C 5)

Inherently Sri Lankan society has displayed a lack of trust and honesty on their followers. This might explain why there is not much trust between entrepreneurs and their employees and vice-versa. However, the following statement made by an entrepreneur emphasises on the importance of human relations and team work for the triumph of a business and to achieve the goals. Further, they believe it is necessary to create a pleasant and a warm working environment.

I got to know that one of the employees is stealing umbrellas. I confronted her and told her that her father, mother and brother all worked for us and how much we helped them. An umbrella was worth only around 50 rupees. I told how much the company would have earned from her and how much we trusted her. As a result of this conversation, that employee stayed with us for nearly 20 years and never stole again. She never lets anyone steal either. (C 2)

This is a very good example where we can see how much he values human feelings and dignity. The insights explore that entrepreneurial values influence on establishing ethical organisation. This is definitely a proof of an intelligent, faithful and a successful entrepreneur. Entrepreneur from case 2 explains his values extended beyond the business as,

A businessman can create good citizens by nurturing good values with the employees. We respect not only our employees but also their 
parents and family. We do not work with machines. We work with hearts and minds of people. If you engage in fraud and theft, your employees would also follow those. First generation of workers worked for their employer but the second generation, for a brand name. My office is open to everyone and anyone can talk to me. My wife comes to the factory and talks to the female workers to see whether they have any issues to be resolved. I also see whether anyone is exerting unnecessary influence over them. (C 2)

Values and discipline differ from employee to employee, whereas some steal and do not return to work ever. A camera system has been fixed in the relevant locations... (C 12)

I think we must take care of our workers. Annually I take their families on a three day trip. We Organise annual pirith ceremony and dana (alms giving). Then they create a bond with the organisation. (C6)

My partners of the company are my family and the people of the company who are excellent. (C 9)

These narrations explain that application of values in business matters are differing from entrepreneur to entrepreneur. The identification and conceptualization of well-being was done in variety of forms by the entrepreneurs. And these concepts were measured from different perspectives. Accordingly it is evident that well-being is a subjective inner quality.

Moreover, interview data reveal that during the initial stage of the business, entrepreneurs do not think about 'what is right or what is wrong'. Entrepreneurs know that some of their practices are not in line with social norms and expectations. Within these grey areas entrepreneurs are compelled to apply their own norms. It is evident that these dilemmas occur at the initial stages of the business. Entrepreneurs from case seven (7), two (2), and four (4) explain their experience as: 
I have faced many difficulties during the initial stage of the business operation. Bankers were not supportive and they did not encourage me to become a retailer and they seemed to think that this was as unsuccessful effort... I am happy today ...I am a contributing towards nation. As an entrepreneur I face everything as a challenge and I believe that time and "patience" as critical factors for success...One can do anything in the first five years. (C 7)

Interview facts disclosed that entrepreneurs in their early stage of business development are so concerned about business survival. So first they think about survival, and then the morality.

\section{Organisational Work Ethics}

Through a comprehensive analysis of interview data, the themes as depicted in Figure 02, were derived. They represent aspects of organisational work ethics which mainly comprises with self-concern (100 percent), egoism (profit concern ( 83 percent), efficiency concern (100 percent), utilitarianism (customer concern (67percent), employee concern (67 percent), and community concern (50 percent)), and deontology (rules concern (100 percent), code of ethics (83 percent) and professional standards (58 percent)).

\section{Practising Egoistic Perspective of Ethics}

Further findings of the study reveal all most all entrepreneurs highlighted explicitly or implicitly their feelings as demonstrating self-concern. However, it does not mean that entrepreneurs are not concerned on sense of others. In particular, entrepreneurs are concerned about their employees and customers and some do not consider much or think about their customers and employees. In terms of motivation, the entrepreneurial community in Sri Lanka moves to make profit and always tend to practise and apply rules and regulations for the business deals.

Right and wrong varies according to the person. I organise myself to achieve the target. (C5)

I believe that what is right and what is wrong do not change from society to society. Truth is the same. (C2) 
All decisions should be based on the organisation not on feelings. I am a person who loves my business the most... We have a good set of rules and regulations governance, discipline and conduct ... yes we follow ethics... (C3)

I went through a lot of difficulties before reaching this level of achievement. My efforts fully revolved around my business. All decisions taken by me...I think my first choice is my business... (C 12)

Do not think I am cunning. Purposefully, I set up my office very closer to the work area. I want to hear the sounds of the machines. Then I know that all the machines are working...I'm not the same person who was back then...(C 6)

I always maintain a considerable distance between myself and the workers. Therefore, we have a strong set of rules and regulations that govern the business. (C 1)

I provide breakfast and lunch for a fair price to the company workers because I believe that due recognition and respect for workers is important. (C 4)

The interview data reveal that most of entrepreneurs give the priority for the business profit and how entrepreneurs treat their employees. It is highlighted some entrepreneurs disrespect for their staff.

If there are many new competitors in the industry it is not a matter for me. I treat them with patience. The information in the company will not be allowed to go outside. If that happens I defeat them strategically (C 3).

Both case six and case one has explained different views with regard to CSR. 
As a company, the main goal is to make profit. Actually we have no CSR policy. However, we have some annual events like pirith chanting ceremony, arms giving etc. (C 6)

I perceive CSR as another business strategy to gain profit. (C 1)

\section{Practising Utilitarian Perspective of Ethics}

According to case six and case one, it shows that without formal CSR policy they engage in some CSR activities. According to Buddhist philosophy arms giving is a symbol of friendship. It is clear that they are practising some positive values which have been derived from positive ethics.

Interview data reveals that entrepreneurial family background, cultural values, economic disparity of the country, regulatory framework, political framework, power and also colonization ideologies have also influenced to such reflected behaviour. Interview data reflected that the culture of social responsibility is not very deeply embedded within the entrepreneurial community in Sri Lanka. Both the organisations and citizens are not used to a culture of corporate social responsibility (CSR). From an organisational point of view it seems to be that CSR is either entirely ignored or used as an elaborate marketing gimmick. Further, entrepreneurs break their organisational rules and regulations and make required allocations in order to achieve business interests and gain a competitive edge. Interviewee from case five explained his practices in regard to CSR as:

I planned to give a quality product. The first priority wasn't profit. We annually do not allocate a sum of money for CSR but whenever such requests are made we look into the possibilities of fulfilling them. (C5)

According to case five, the entrepreneur is practising a balanced approach. He compromises company interest and social interest. He tries to do something to the society. Case 4 explained his perception about CSR as:

We pay tax duly to the government...I believe it is our duty. I am conducting workshops, seminars and teach at technical colleges, ....My aim is to create awareness of how to start a business,... Share 
my experience, teach and give knowledge to who are interested in this business or another business. (C 4)

The above view shows that their inner feeling is to do something for the society. These services are provided free of charge. The entrepreneurs do these with clear morals or for the sake of optimizing social responsibility in order to gain recognition which would benefit the success of their businesses. Hence, they seem to be extrinsically caring about their own wellbeing. Following explains the interviewee's behaviour (by an outsider).

He doesn't help community as much as he talks. We notice he (i.e., Case 4) doesn't even give an appointment to meet him. We know well that the workers are not happy and they also suffer a lot, most of them stay only for three or four months and they don't return to work.

There is a major disparity between the entrepreneurs' professed values and practised values. The entrepreneurs in their interviews claimed to follow rules and regulations, practices, community care, follow government imposed tax principles, support institutional network building, and are concerned about customer care and self-well-being. Yet, their practices showed that they do not follow ethical values in relation to their beliefs as they are driven by profit maximization. Therefore, the practised values reflect a negative set of values that contradict the values that they claim to have.

Considering all insights, three entrepreneurial clusters were identified. Cluster one includes entrepreneurs who are driven by knowledge acquired through the basic socialization process at home where the parents have taught them what is right and what is wrong, based on the fundamental principles of religion that they have believed from birth. Cluster two, the entrepreneurs at the same time define ethicality in terms of their own understanding of it, specially highlighting their self-concern needs. The third cluster, the entrepreneurs are driven by complexities of the history experienced in Sri Lanka and they prefer to practise profit maximization. The final outcome shows that rather than a dominant single ethicality, a combination of ethicalities was preferred by most entrepreneurs. Within this mix of ethicalities, deontological ethicality and egoistic work ethicality 
seem to be equally practised by the entrepreneurs and utilitarian work ethicality seems to be practised by the entrepreneurs at a minimum level.

The insights show that the values and beliefs deeply reinforce as to what is right and what is wrong. Values direct their actions and enable entrepreneurs to create ethical relationships with others and assist them to response to internal and external pressures. In line with the facts disclosed in the interviews, it is evident that most of the entrepreneurs are governed by a set of values that they have internalised over the years. One such is selfcentered and autocratic decision-making. Moreover, it is evident that the existence of values, for instance, the need for achievement, innovation, selfconfidence, risk bearing, locus of control, honesty, trust and openness have been conceptualised in the entrepreneurial context in Sri Lanka. Moreover, values play an influential role in entrepreneurial decisions and it provides the foundation for ideologies related to ethics. Shafer et al. (2007) support this view. Besides, the study re approves the findings of Longnecker et al. (1988), that ethics is embedded in the main characteristics of the entrepreneur. The analysis explored different types of relationships among entrepreneur and business, customers, employees, competitors, government and society at large. Morris et al. (2002) verify the outcome of those. Further, data collected through interviews exposes the level of ethicality of the decisions dependent on the nature of the relationship between entrepreneur and the stakeholders.

Qualitative insights show that the entrepreneurs play a vital role in developing ethical background in the organisation. However, at the beginning, an organisation generally shows some form of consistency with its principles, values and behaviour. Accordingly, in the process of development of the organisation the following attributes could be observed: trusting others through own authenticity and follow and maintain honest relationships, maintain professional conduct, protect general public and internal security, share benefits with others, follow organisational policies consistently and fairly, admit personal mistakes and organisational mistakes, communicate openly and honestly with employees and customers, represent information and data accurately and completely and also demonstrate personal commitment to employees and care about their health and safety. The end result of this organisational process enables to demonstrate the 
entrepreneurs' principles and business ethics to the stake holders and the entire business world.

Organisational ethicality is concerned about employee aspect as a focal point. The entrepreneur in case 2 genuinely explains his views and practices in relation to his employees as follows:

My friend died in 1990. Then, my friend's wife and brothers became business partners and later they wanted to divide the business. We divided the business fairly among the partners. Ownership of factories was given to the friend's family. I retained the staff, machines and materials. Although his family received the best of assets, I got the best of human resources.

This entrepreneur believes human resource is the most important and the most valuable resource and was wise enough to take them into his hands as intellectual property encompasses expressions of ideas, thoughts, codes and information. Human qualities are highly valued by this entrepreneur.

I think trust is very important. Business is built on the notion of trust. A learning process takes place within a working place. We should master every step in the business process. Trust is something invisible but it is essential to build our lives and the businesses. I get angry only with my wife because I know she is the only one who would not leave me whatever happens. Others may leave me if they get irritated with me. (C 2)

The principles of our business are, share and care, win hearts and accept challenges. We need commitment to succeed and the ability to change is also important. When there are problems, we come together and find solutions. Our aim is to make quality citizens. To make a quality citizen, a nurturing environment is needed. (C 4)

The above facts reveal that the cognitive style of entrepreneurial thinking and risk preference on entrepreneurial self-efficacy and entrepreneurial intensions. Further, it shows that high risk preferences gain high rewards and a higher level of entrepreneurial intentions. Further, 
insights of these interview facts explain that entrepreneurs are extremely target oriented and they know what is right and what is wrong. However, the risk may be a potential for harm, discomfort or inconvenience (Mauro, Natale \& Libertella, 1999). Further, taking high risk may created: physical harm such as injuries, illness or pain; Psychological harm such as distress, guilt, anger and disrespect; social harm such as damage to social network, discrimination; economic harm for instance increased social cost; legal harm like criminal cases, misconduct and fraud. In fact, among these incidents some are to some extent visible in the workplaces. Emerging interviewees (employees) of some organisations said that they are not working happily and also entrepreneurs state that employee turnover is high.

The concepts of trust and honesty are fundamental to any organisation. Without trust and honesty the life of a business will be a formidable challenge. Babalola (2009), states that the freedom of a business to make profit is limited by the values of fairness, equal opportunities, honesty and truthfulness. Insights of these facts reflect that without inter personal relationships in terms of trust and honesty, organisational ethicality is problematic. Because of, all entrepreneurial decisions are made and based on these relationships. However, trust aligned with honesty will assist to develop effective working relationships and can give its stakeholders what is due to them and ethical standards too are clear.

Entrepreneurs have to survive in a competitive environment. According to the facts revealed by the interviewees it shows that during the startup stage of a business they face many difficulties. It is obvious that to survive in the grey area of the business life cycle, sometimes they have to violate their values to protect the business. In fact, at the initial stage of a business, entrepreneurs do not think "what is right" or "what is wrong". Entrepreneurs know what some of their practices are not in-line with social norms.

Within these grey areas entrepreneurs are compelled to apply their own rules and regulations to establish and conduct a business. It is evident that these ethical dilemmas which occur at the initial stages of business practices are governed by unwritten regulations which are blended with the entrepreneurs' self-interest. These findings are in line with the literature as, Burton and Goldsby (2005) states that business people might not consider 
ethics, but consider the benefits to oneself and also, they reveal that business people make decisions with no clear standards to be used as guidance (Burton \& Goldsby, 2005). Goodpaster (2007), Trevino et al. (2004), Fisher and Lovell (2003) have also informed that in reality it is not easy to judge whether an action is right or wrong in business as it apparently creates ethical dilemmas for the business.

It reveals that entrepreneurs do not consider the health and safety of their workers or environment pollution. That is why they do not insist on their workers wearing safety items. If they are concerned about the basic requirements of employees, they would have to force the employees to use those safety items. Further, if they are concerned about environmental pollution they will have to use the latest technology to protect their employees as well as their factory environment. We cannot argue that these practices are completely wrong if that practise affected the performance of the business. According to the history of Sri Lanka, most of the workers were reluctant to use safety equipment as they were more comfortable to perform their job without safety equipment. The reason for this is due to the fact that most of the Sri Lankan workers were from agricultural community.

But the employees do not like to wear safety equipment once they get used to it and we do not force them to use them either. I expect people to be well disciplined and to do their job responsibly. Each team has a target and they must attain their targets (C 5)

We can't think both about our health and the future, we have to work hard to earn something more for our living. So we work for them (an emerging interviewee). First we recruit employees on contract basis and after six months we extend the work agreement for another six months. If we no longer needed such labor we terminate them, then we can reduce unnecessary labour issues...(C 1)

Case eight (8) and twelve (12) also had the similar opinions in this regard.

It is clear that present day business employees at the operational level are more concerned about what they get at the end of the month rather than the letter of appointment and the duty list. Also organisations tend to recruit 
operational level staff for a period of six months and after breaking the period they are listed under new Employee Trust Fund (ETF) and Employee Provident Fund (EPF) numbers. Legally, invisible, such practices are to avoid the employees' benefits, minimise organisational cost and avoid unionization of employees. However, according to Social Accountability 8000 (SA 8000) published by SAI, collective bargaining is a right of the workers.

Moreover, the psychological aspect of this scenario is that the employees do not have job security and as after every six months he/ she is considered a new employee to the organisation. In the Sri Lankan context, engaging in a job and earning money are essential for life. If one does not have means of livelihood the individuals are disturbed and they live unhappily and under stress. According to hierarchy of needs theory of Maslow, it says all individuals have some needs and they are in a hierarchical order. First, the individual tries to fulfill his/her basic needs and after that he/she expects to fulfill security needs. Organisations have obligations to identify these human needs and help employees to fulfill those needs. Although these retention practices of entrepreneurs are legally right, there is a major concern about their ethicality. It is clear that at present context the work of the entrepreneurs is legally smart but ethically painful for the workers and also this is practised by the entrepreneurs knowingly as they are very much aware of the legal requirements of employee recruitment. It is clear that the entrepreneurs in the business context take advantage of loopholes in the legal system of the country and ignore the needs and wants of their employees. Interviewees from case six (6), eight (8) and twelve (12) explain their business practices as,

Appointment letters are not issued for the factory workers. They are issued for office staff only. First we recruit employees on contract basis and continue his or her service... We strictly follow rules and regulations. Every month I allocate duties among. The workers and I always keep track on each and every step that's taken by the employees in order to maintain the profit margin.

Issuing an appointment letter to an employee is an obligation of the employers. But it is not practised in this company, and it shows the 
negligence of the responsibility of a good entrepreneur. His unethical practice shows that he refuses to make any kind of legal bond between the workers and the company. Entrepreneurs explain their current practices with regards their employees as,

I do not pay EPF (Employee Provident Fund) and ETF (Employee Trust Fund). Our workers are so poor. They do not think about their future. They are concerned only about taking home their salary. $(C$ 12)

We pay salaries for employees. That means we have purchased their labour. Hence, they should work for us. (C 11)

The company policy is that they follow the government approved pay system for the workers which cause no trouble in dealing with ethics and norms. (C 6)

The above facts indicate that there is no humane relationship between employers and employees. It is only a financial transaction which takes place in between two parties. Although it is true that Sri Lankan labourers are poor and concerned only about taking home their salary, entrepreneurs have taken this vulnerability as an opportunity for them not to pay the contribution of the employer to EPF and ETF. However, it is questionable because this decision is morally right if it is implemented based on the employees' request. Yet it is morally wrong if it is implemented as the entrepreneur's own decision.

\section{Deontological Work Practices}

However, since the rules seem to serve both the employer and the employee, the deontological character cannot be called one-sided. Though what the entrepreneur says in the above statement indicates that he follows the rules and regulations, the real question is who makes the rules and how fair the rules are to ever party in a business. The tone of his voice gives the idea that it ultimately serves an egoist purpose. The adherence to universal standards and beliefs which are concerned with the applications and rules, regulations and law during the process of decision making are highlighted. 
(Lemmergaard \& Lauridsen, 2008). Entrepreneurs explain their preference towards rules as,

We have a good set of rules and regulations governing attendance, discipline and conduct. ( $C$ 1)

In addition to the rules and regulations in my organisations, addition to the I have applied advance technological systems such as finger print machines, security alarm, security personals as well"(C 6). I believe that all the business organisations should have well set up rules and procedures. $(C 7)$

We have a strong set of rules and regulations that govern the business. And in my organisation people are expected to follow and obey the rules and regulation without any failure. (C 5) 
Figure 1 : Thematic Network-Values

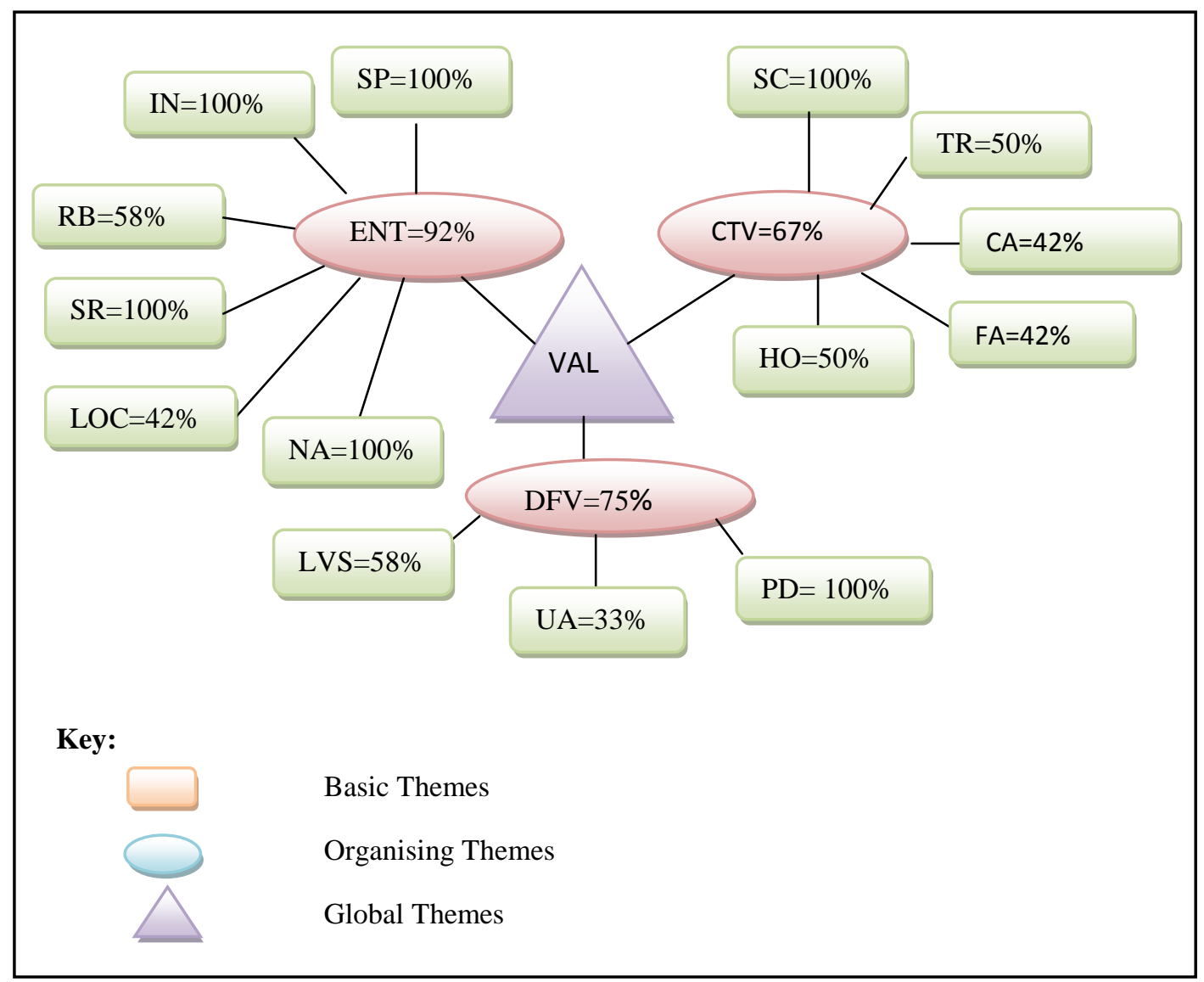

Source: Author Constructed based on Interview Data

Note: Themes: $E N T=$ Entrepreneurial Values, $C T V=$ Contextualised Values, DFV $=$ Defensive Values, $N A=$ Need for Achievement, $S P=$ Social Power, $S R=$ Social Recognition $I N=$ Innovation, $L O C=$ Locus of Control, $R B=$ Risk Bearing, $T R=$ Trust, $C A=$ Care, $F A=$ Fair, $H O=$ Honest, $S C=$ Self Confidence, $L V S=$ Long Term vs Short Term, $P D=$ Power Distance, $U A=$ Uncertainty Avoidance 
Figure 2: Thematic Network-Organisational Work Ethicality

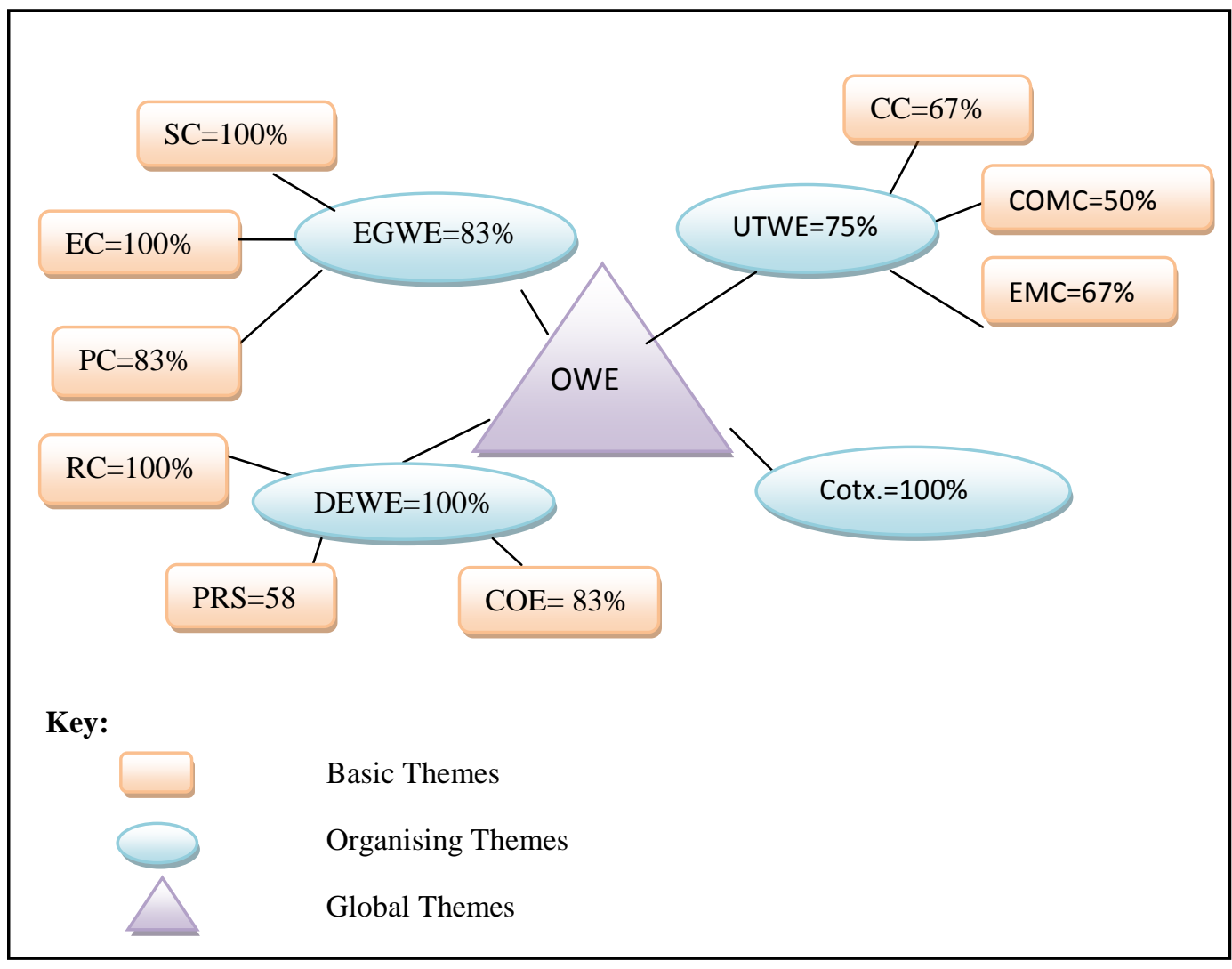

Source: Author Constructed based on Thematic Analysis

Note: Themes: $O W E=$ Organisational Work Ethicality, EGWE- Egoistic Work ethicality, $U T W E=$ Utilitarian Work Ethicality, $D E W E=$ Deontological Work Ethicality, $S C=$ Self Concerns, $E C=$ Efficiency Concerns, $P C=$ Profit concerns, $C C=$ Customer Concerns, $C O M C=$ Community Concerns, $E M C=$ Employee Concerns, $R C=$ Rule Concerns

Managing the employees in a workplace effectively necessitates that even the smallest of businesses set up work rules. Work rules protect a business and workers and if correctly implemented and executed, create and maintain a better working environment for all. But here the respondent did not mention who has the power of making these mentioned set of rules where it seemed to be that there has been no opportunity for the workers to come up with their suggestions to set the objectives. Since no implication has been done on benefitting the workers it suggests that this entrepreneur showcases qualities of a dictator. According to this, it seems to be that he 
does not practise honesty and trust in the working environment. Most of the entrepreneurs provide meals for their employees for a small price with a view of running the business more smoothly. This cost is incurred entirely for business purposes. It makes the employees available at all times of the day, and to makes it easier for employees themselves as they do not have to be late for work since they can buy meals from the workplace itself for a reasonable price. Making the employees lives easier makes them happy and making them happy create trouble free working environment.

The employer and employee relationship is vital for deriving organisational ethicality. The facts reveal that the aforesaid relationship has become more complex in the context. Distrust, employee discrimination, unfairness, ignorance of the work place safety, lack of respect, cheating, were found as bad practices at the workplace. But the economic back ground, cultural values like, respecting the employer, forgiving, being patient and, friendly, and working in a team are the positive aspects of the practices. The income, poverty, culture, education level, profit concern, power and weakness of the regulatory system of the country and conflict of interest are the root causes leading to this situation. The entrepreneurs' major concern is to achieve optimum levels of productivity and performance. The ethical practices overshadow cultural boundaries.

In the Sri Lankan context, the above said behavioural patterns are derived from their socio - economic status such as poverty, minimal levels of education, and other socio cultural obligations related to their family responsibilities. These factory workers do not pay much attention to the business ethics of an organisation. Instead, they are mainly concerned about their responsibilities towards their family and their other social relationships. Since the employers know the intension of the workers, they try to maximise the work load and the employees are only driven by the payments they receive. This scenario explains the conflict of interests of both the entrepreneur and the employees in the organisation. However, the situation of office employees is somewhat different from the status of the factory workers. The employees of an office bureau receive a certain consideration from their employer mainly due to their educational background. It seems that employees of an office bureau are more concerned about business ethics and the responsibilities of the entrepreneur 
other than the salary. From the entrepreneurs' perspective their business is the main valuable asset that they have for their sustainability. The strength of an entrepreneur i.e. status, reputation, social recognition, social and family obligations, and health rely upon his level of business. Therefore, the protection of his own business is key responsibility of an entrepreneur. It is difficult to state that the decisions that are taken by the entrepreneurs to protect their business are wrong but it is felt that there is room for improvement.

The entrepreneur is the person to whom the employees look for information about what is right and wrong for the organisation. Therefore, it is important for the entrepreneurs to establish and communicate a vision for the enterprise, inspire commitments and encourage pride in working for it. Pride builds dignity and self-respect, as employees are proud of where they work and what they are doing. Inequality of need, scarcity, and inequality of human power, limited altruism may cause to create real problems in working place. They hope for due respect for them from their employer. The organisations need to consider and treat their employees with disrespect and distrust; chances are they do the same towards you.

When analyzing the nature of relationships between present practices and reality, CSR is another important aspect of business ethics. At present business context entrepreneurs are aware of the significance of CSR and their responsibility of adopting and practicing CSR to facilitate social wellbeing of the community at large.

Social responsibility is a concept which binds the organisation and the society together. In entrepreneurial standpoint he/she stays behind two types of social obligations towards society. One is as a citizen of the country and other is emerging social obligations to well-being of the society through his/her business operations as an entrepreneur of the country. One of the organisation's primary goals is its obligation to operate in a socially responsible manner (Carroll \& Shabana, 2010). Kurucz et al. (2008) recognised that four types of advantages: (1) cost and risk reduction; (2) gaining competitive advantages; (3) developing reputation and legitimacy; and (4) seeking win-win outcomes through synergetic value creation that organisations may achieve from undertaking in CSR activities. Davis (1973) 
states that in order to respond effectively and efficiently to the major social issues and the demands of the day, social policy must be integrated to the corporate strategy. It is clear that CSR activities may assist organisations strengthen its legitimacy and reputation and also enable the organisation to meet the competing needs of its stakeholders while earning profit. According to the interview data has shown in most Sri Lankan entrepreneurs is not much concern about CSR and they do not have any consciousness about the importance of CSR to their business success. Therefore, Sri Lankan entrepreneurs need to think and incorporate CSR activities for their master plan.

The Sri Lankan government is encouraging businesses to adopt sustainable development by creating awareness and motivating them to minimise pollution and at the same time to minimise the use of resources such as energy and water. This would finally result in achieving the triple bottom line. The present world scenario is to protect the triple bottom line which is profit (economic), people (social) and the planet (environment) which will ensure the development of ethically friendly business entities.

Being concerned about the customer is a focal point of organisational ethicality. It is proven by the quantitative analysis. But the interview data reports that in certain situations entrepreneurs consciously and knowingly use low quality or banned materials in the production process in order to make higher profits. In fact, even multinational corporations which boast of good ethical practices set by the parent companies violate business ethics in third world countries like Sri Lanka. This sets unethical standards for the emerging young entrepreneurs of the respective sectors of the country.

When we look at the status of employees in the Sri Lankan business context, the basic criteria for their salaries and other benefits depend on their education and qualifications. The contribution towards final product quality and adhering to company objectives and targets are not considered. As such a culture of discrimination prevails. This practice is so ingrained in society that none would even dream of challenging this practice. 


\section{Research Contribution}

The findings of the study provide a theoretical and practical insight into understanding the extent of values incorporated in business practices and the type of work ethicality reflected in Sri Lankan business organisations This study provides a useful preliminary framework for understanding the present level of ethical commitment of an organisation to maximizing social well-being and also for theory building and theory testing on these challenging themes related to values, ethics, and ethical climates in the Sri Lankan entrepreneurial context. The majority of entrepreneurs of the country think they behave well but the findings of this study in general provide a deeper understanding of entrepreneurial values and ethical practices that exist in the context and also serve as a valuable selfassessment tool, helping entrepreneurs to determine to what extent their organisations are operating to maximise social well-being. Entrepreneurs would also be able to reevaluate where they aspire to be while pursuing their objectives.

Furthermore, the findings would help decision makers: at organisational level and policy making level to rethink and establish context sensitive mechanism to improve ethical aspects of the businesses in order to maximise social well-being of the country while doing the right things for society and protecting shareholder interests. The current study provides further evidence that may contribute to developing an ethical framework for business organisations.

The study findings would empower the relevant authorities to address the nation's requirement; that is, to develop entrepreneurial skills in the younger generation so that they would start successful business ventures and become pillars of the development of the country. There is a need to introduce new entrepreneurial development programmes and enhance the existing entrepreneurial development programmes in order to meet the country's requirements. Unfortunately, many state organisations and financial institutions conduct poverty reduction programs under the banner of entrepreneurship development but they target only a limited segment of society. Hence, they cannot be considered as adequate entrepreneurial development programmes and they often fail to implement such projects successfully due to financial and nonfinancial constraints. From an 
institutional point of view, they also fail to achieve the intended results through the projects they launch. Therefore, it is essential to select prospective entrepreneurs with proper entrepreneurial inclinations or to inculcate and develop entrepreneurial traits and ethics in their minds before selecting them for entrepreneurial development programmes. Ultimately, if these programs succeed, they would create the next generation of ethically solid entrepreneurs for the country and they would add value to society. Personality characteristics can change over time; it is possible to increase the motivation to become an entrepreneur through training programmes which then, in turn, will increase business performance (Andrease \& Michael, 2000). Therefore, this study could be used as a basis.

In Sri Lanka, it is important to adopt a multi-cultural and multi religious approach and thereby iron out the gap in business relations through the development of values, ethics and practices. Introducing ethical practices and being aware of ethics may help to reduce the gap between different ethnic and religious groups.

In the future, themes and methodology can be extended to different sectors, different disciplines or different professions to examine how they deal with the ethical dilemmas. This area could be a field of interest for researchers who would like to look into real practices in entrepreneurship.

\section{Conclusion}

Qualitative insights reveal that entrepreneur's behaviour is mirrored multifaceted interactions between the individual and the business which has to be energetic because business situations are always fluctuating. Entrepreneur's judgments and his/her behaviour are critical and vital in each of these situations. Also entrepreneurs' judgments and behaviours are most frequently guided directly or indirectly derive from their expectations. In the present study all six variables: need for achievement, social recognition, social power, innovation, locus of control, and risk bearing have been examined with organisational work ethicality. The most important finding of this study is that these specific components or variables of entrepreneur's attributes or traits are significant and direct predictors of organisational work ethicality. Further these attributes indirectly influenced egoistic work 
ethicality, utilitarian work ethicality and deontological work ethicality in the business.

Values such as honesty, trust, care, fair, equality are a derivative of the concept of ethical relativism. Ethical relativism identifies ethics and moral judgment as context specific. Depending on socio cultural and historic factors, societies develop and adhere to their own unique set of attributes. These may manifest in terms of divergent social factors and social appraisals. Descriptive relativism describes these practices in terms of socio logical features whereas normative relativism delves into the underlying judgments behind the said sociological differences.

Business practices are shaped by their definition of the concept of profit, success and social responsibility. The values and priorities determine the way in which people perceive, interpret and commit themselves to determine such practices. In the contemporary world of business, individual levels of business practices appear as a dichotomy between egoism vs. altruism (self-interest vs. being concerned about others) and at organsational level, it could be differentiated between profit and nonprofit and the level of society or the comparison between social values or social well-being against organisational well-being. Therefore, ethicality in business practices has become a paradox.

\section{References}

Al-khatib, J.A., Rawwas, M.Y.A., \& Vitell, S.J. (2004). Organizational ethics in developing countries: A comparative analysis. Journal of Business Ethics, 55(4), 309-322.

Andrease, R., \& Michael, F. (2000). Psychological approaches to entrepreneurial success. International Review of Industrial and Organizational Psychology, 15, 45-60.

Babalola, S.S. (2009). Determinants of unethical business behavior among owner-managers. Journal of Human Values, 15(1), 61-75.

Becker, H., \& Fritzsche, D. (1987). A comparison of the ethical behavior of French and German managers. Journal of World Business, 22(5), 95110.

Braun, V., \& Clarke, V. (2006).Using thematic analysis in psychology Qualitative Research in Psychology, 3(2), 77-101. 
Brett, J. A., Heimendinger, J., Boender, C., Morin, C., \& Marshall, J. A. (2002). Using ethnography to improve intervention design. American Journal of Health Promotion, 16, 331-340.

Burton, K. B., \& Goldsby, M. (2005).The golden rule and business ethics: An examination. Journal of Business Ethics, 56,371-383.

Carroll, A.B., \& Shabana, K.M. (2010). The business case for corporate social responsibility: A review of concepts, research and practice. International Journal of Management Reviews, doi:10.1111/j.14682370.

Chandraraya, H. (1958).Ceylon history, University of Vidyalankara, Sri Lanka.

Chowdhury, R., \& Fernando, M. (2010). The relationship between spiritual well-being and ethical orientation in decision making: An empirical study with business executives in Australia. Journal of Business Ethics, 95, 211-225.

Davis, K. (1973). The case for and against business assumption of social responsibilities. Academy of Management Journal , June, 312-322.

Deem, R. (2002).Talking to manager- academics: Methodological dilemmas and feminist research strategies. Journal of Sociology, 36, 835-855.

Dias, S. (1987). Industrialisation strategy in Sri Lanka recent changes in policy and promotional measures Sri Lanka. J.S.S, 10 (1 and 2), pp. 51-82.

Fisher, C., \& Lovell, A. (2003). Business ethics and values, FT Prentice Hall.

Goodpaster, K. (2007). Conscience and corporate culture. London: Blackwell.

Hisrich, R.D. (1998). Ethics of business managers vs. entrepreneur: An international comparative study. Working Paper, Weatherhead School of Management, Washington.

Jayewardena, K. (2000).The rise of the colonial bourgeoisie in Sri Lanka. Nobodies to Somebodies, Colombo: The Social Scientists' Association.

Karunarathna, H.D. (2009). Internationalization of Sri Lankan Entrepreneurship - A study of Sri Lankan immigrant entrepreneurs in Japan. Faculty of Management and Finance, University of Colombo.

Koivula, N. (2012). Basic human values in workplace. Department of Social Psychology, University of Helsinki.

Kuratko, D. F., Goldsby, M.G., \& Jeffrey, S. (2004). Ethical perspectives of entrepreneurs: An examination of stakeholder salience. Journal of Applied Management and Entrepreneurship. Retrieved fromhttp://findarticle.com/p/articles/mi_qa5383/is_200410/ai_n2134 2851/pg_3/?tag=conten. Accessed on 1/6/2010. 
Kurucz, E., Colbert, B., \& Wheeler, D. (2008).The business case for corporate social responsibility. The Oxford Handbook of Corporate Social Responsibility. Oxford: Oxford University Press.

Lemmergaard, J., \& Lauridsen, J. (2008). The ethical climate of Danish firms: A discussion and enhancement of the ethical-climate model. Journal of Business Ethics, 80,653-675.

Longencker, J.G., McKinney, J.A., \& Moore, C.W. (1988). Ethical Issues of Entrepreneurs. Texas: Baylor University.

Mauro, N., Natale, S. M., \& Libertella, A. F. (1999). Personal values, business ethics and strategy development: Cross cultural management. An International Journal, 6 (2), pp. 66-78.

Mayer, D.M., Kuenzi, M., \& Greenbaum, R. L. (2010). Examining the link between ethical leadership and employee misconduct: The mediating role of ethical climate. Journal of Business Ethics, 95, 7-16.

Miglino, B. M., \& Ravlin, E.C. (1998). Individual values in organizations: Concepts, controversies and research. Journal of Management, 24(3), 351-389.

Morris, M.H., Schindehutte, M., Walton, J., \& Allen, J. (2002). The ethical context of entrepreneurship: Proposing and testing a developmental frame work. Journal of Business Ethics, 40(4), 331-361.

Nanayakkara, G. (1984). Cultural imperatives of policy science. Vidyodaya Silver Jubilee Issue, 85-103.

Paranavitana, S. (1966). Archaeological survey of Ceylon. Epigraphia Zeylanica, V, 178-194.

Patton, M. Q. (1990/2002).Qualitative research and evaluation methods. $3^{\text {rd }}$ Edition, California: Sage Publication.

Perera, T. (1996). The need for affiliation as a moderator in the behavior of entrepreneurs. Sri Lankan Journal of Management,12-22.

Perera, T., \& Buddhadasa, S. (1992). Characteristics of Sri Lankan entrepreneurs: How valid is the Schumpeterian model? PIM Conference on Management Studies, BMICH, Colombo, December 15-18.

Perren, L., \& Ram, M. (2004). Case study method in small business and entrepreneurial research. International Small Business Journal, 22, 83-100.

Premaratne, S.P. (2002). Entrepreneurial networks and small business development: The case of small enterprises in Sri Lanka. Eindhoven, NL: Technische Universiteit, Eindhoven.

Roccas, S., Sagiv, L., Schwartz, S. H., \& Knafo, A. (2002). The big five personality factors and personal values. Personality and Social Psychology Bulletin, 6, 789-801. 
Rockeach, M. (1973).The nature of human values. New York: The Free Press.

Roe, R.A. (1999). Values and work: Empirical findings and theoretical perspective. Applied Psychology: An International Review, 48(1), 121.

Schwartz, S. H. (1994). Are there universal aspects in the structure and contents of human value? Journal of Social Issue, 50(4), 19-45.

Schwartz, S.H., \& Bilsky, W. (1987).Toward a universal psychological structure of human values. Journal of Personality and Social Psychology,53(3), 550-562.

Senadheera, G.D.V.R., Gamage, H.R., \& Karunaratne, H.D. (2014). Value driven Asiatic entrepreneurship: South Asian way of ethical entrepreneurship and sustainability. Journal of Process Management and Benchmarking, 4(3), 277-291.

Shafer, W.E., Fukukawa, K., \&Lee, G.M (2007). Values and the perceived importance of ethics and social responsibility: The U.S. versus China. Journal of Business Ethics, 70, 265-284.

Stirling, J. A. (2001). Thematic networks: An analytic tool for qualitative research. Qualitative Research,1(3), 385-405.

Trevinco, L., \& Nelson, K. (1999). Managing business ethics: Straight talk about how to do it right, New York: Wiley.

Trevino, L.K., Brown, M., \& Hartman, L. (2004). A qualitative investigation of perceived ethical leader ship: Perceptions from inside and outside the executive suite. Human Relations,56,5-37. 
